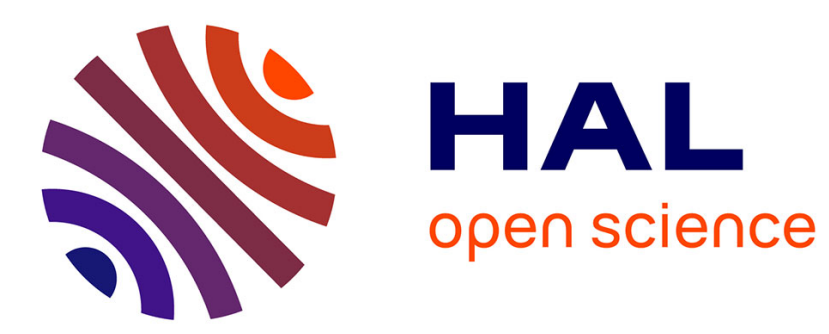

\title{
Modelling of long-term dynamic leaching tests applied to solidified/stabilised waste
}

\author{
Laurent de Windt, Rabia Badreddine
}

\section{To cite this version:}

Laurent de Windt, Rabia Badreddine. Modelling of long-term dynamic leaching tests applied to solidified/stabilised waste. Waste Management, 2007, 27 (11), pp.1638-1647. 10.1016/j.wasman.2006.07.019 . hal-00596540

HAL Id: hal-00596540

https://hal-mines-paristech.archives-ouvertes.fr/hal-00596540

Submitted on 3 Nov 2015

HAL is a multi-disciplinary open access archive for the deposit and dissemination of scientific research documents, whether they are published or not. The documents may come from teaching and research institutions in France or abroad, or from public or private research centers.
L'archive ouverte pluridisciplinaire HAL, est destinée au dépôt et à la diffusion de documents scientifiques de niveau recherche, publiés ou non, émanant des établissements d'enseignement et de recherche français ou étrangers, des laboratoires publics ou privés. 


\title{
MODELLING OF LONG-TERM DYNAMIC LEACHING TESTS APPLIED TO SOLIDIFIED/STABILISED WASTE
}

\author{
Laurent De Windt ${ }^{(\mathrm{a})}$, Rabia Badreddine ${ }^{(\mathrm{b})}$
}

(a) Ecole des Mines de Paris (ENSMP), CIG-Hydrodynamics and Reaction Groups, 35 R. St-Honoré, 77300 Fontainebleau, France.

(b) National institute for industrial environment and risks (INERIS), DRC, Parc Technologique Alata BP2, 60550 Verneuil-en-Halatte

Corresponding author. Email: laurent.dewindt@ensmp.fr

\begin{abstract}
The paper aims at simulating the dynamic leaching of a cement-based monolith containing lead with the numerical reactive transport code HYTEC in a 3D-cylindrical geometry. The model considers, simultaneously, the chemical evolution of pore water, the progression of mineralogical alteration fronts, and the concomitant release of elements from the S/S waste. In good agreement with experiment, element releases were found to be mainly controlled by either diffusion ( $\mathrm{Na}, \mathrm{K}$, and, to a lesser extent, $\mathrm{Cl}$ ), by surface dissolution $(\mathrm{Ca}, \mathrm{Si})$ or by a mixed evolution $\left(\mathrm{Pb}, \mathrm{SO}_{4}\right)$. All the calculated mineralogical transformations take place in a thin layer beyond the monolith surface. Consequently, modelling of $\mathrm{Ca}, \mathrm{Si}$ and $\mathrm{SO}_{4}$ releases was quite sensitive to the node size of the simulation grid and was improved by taking into account the increase of porosity and effective diffusion coefficient due to mineral dissolution in the leached layer. In agreement with experimental results, the deepest front corresponds to portlandite dissolution and $\mathrm{CSH} 1.7$ transformation into $\mathrm{CSH}$ of lower $\mathrm{Ca} / \mathrm{Si}$ ratio. A second, distinct and intermediate, front is made by ettringite dissolution. The network of CSH is globally preserved in the leached layer, complete dissolution occurring over a very small thickness only. Finally, hydrotalcite precipitation in the leached layer is expected by modelling due to $\mathrm{pH}$ drop.
\end{abstract}

\section{Keyword}

Cement, leaching test, reactive transport, solidified waste 


\section{Context and objectives}

Cement-based materials are commonly used for the solidification and stabilisation of toxic metal waste ( $\mathrm{S} / \mathrm{S}$ waste) since they have good physical as well as chemical containment properties. As water is the main environmental pollution vector, their short and long term behaviours in the scope of disposal and recycling scenarios are evaluated by extensive leaching tests. Batch leaching experiments, performed over short durations on crushed materials, are a simple tests useful for determining the intrinsic properties of the waste with respect to one or several controlled parameters. Dynamic leaching tests, made on monolithic samples, are more specifically used to determine the long-term waste evolution and pollutant release under accelerated alteration processes. Coupling between diffusion, dissolution/precipitation and sorption processes has been clearly identified during such leaching of cement-based waste (Atkinson and Nickerson, 1988; van der Sloot, 1996; Tiruta-Barna et al., 2004), thus requiring reactive transport modelling.

Beyond the quantification of release rates, modelling is of primary importance for the understanding of long term release mechanisms but also for the extrapolation of laboratory results to site conditions characterised by lower solution/solid ratios, site specific geometry, cyclic infiltration, etc. (Baranger et al., 2002; Tiruta-Barna et al., 2004). Considerable progress has been made in the field of reactive transport models and computer codes which offer the possibility of simulating geochemically complex systems in a hydrodynamic context (van der Lee and De Windt, 2001). However, to our knowledge, there are only a very few models of $\mathrm{S} / \mathrm{S}$ dynamic leaching currently available in the literature. Halim et al. (2005) developed a comprehensive geochemical model of S/S waste batch tests using the PHREEQC numerical code, but for crushed materials without considering diffusion. Park and Batchelor (2002), Garrabrants et al. (2003) and Tiruta-Barna et al. (2005) addressed the modelling of dynamic leaching tests on monolithic cement-based waste with their own numerical reactive transport model, in 1D coordinate and without explicitly simulating the mineralogical fronts in the monolith. Islam et al. (2004b) developed an analytical two-front leach model for cement-stabilised heavy metal waste in the simplified case of spherical particles.

The work presented in this article attempts to address some of the limitations of these previous studies, simulating the dynamic leaching of a cement-based monolith containing lead with the numerical reactive transport code HYTEC in a 3D-cylindrical geometry. The model considers, simultaneously, the chemical evolution of pore water, the mineralogical alteration fronts induced by the sequential dissolution of the cement hydration products, and the concomitant release of elements from the $\mathrm{S} / \mathrm{S}$ waste. In addition, HYTEC takes into account the increase of porosity and effective diffusion coefficient in the leached layers of the monolith. This important feedback effect was generally not considered in the above mentioned studies. Special attention is also given to the sensitivity of the calculated results with respect to the refinement of the grid. The initial state of the $\mathrm{S} / \mathrm{S}$ monolith is modelled on the basis of mineralogical analyses and two standardised batch tests (maximum mobile fraction and acid neutralisation capacity).

\section{Materials and model features}

\subsection{Material and experiments}

The porous reference material was obtained by solidification of $1 \%$ lead by weight, introduced as a chloride salt, with a mixture of $3 / 4$ siliceous sand and $1 / 4$ Portland cement CEM-I by weight, a common industrial process for hazardous waste stabilisation. There was no addition of calcium carbonate. The sand was a mined material consisting of reactive amorphous silica with some cristobalite, opal and quartz. The water/cement ratio was slightly below 0.6. These components were cold mixed and cured at room temperature during 28 days. Calcium silicate hydrates (CSH), portlandite and sulfo-aluminates constitute the main cement solid phases. The $\mathrm{S} / \mathrm{S}$ waste was dry cut in small cubic monoliths $\left(4 \times 4 \times 4 \mathrm{~cm}^{3}\right)$. The 
mean total porosity was about $15 \%$ according to $\mathrm{Hg}$ porosimetry measurement $(75 \%$ of the total porosity being related to pore diameters $\leq 1 \mu \mathrm{m}$ ).

In a first stage, two batch leaching tests were performed on finely crushed materials (diameter $\leq 1 \mathrm{~mm}$ ) in an airtight device to avoid carbonation with continuous stirring and under constant temperature $\left(20^{\circ} \mathrm{C}\right)$. The data obtained during an acid neutralisation capacity test (ANC) was used to determine lead solubility as a function of $\mathrm{pH}$. The ANC experimental method consists of contacting the crushed material with a leachant volume at a constant $\mathrm{pH}$ and liquid/solid ratio $(\mathrm{L} / \mathrm{S}=10)$. Nitric acid and sodium hydroxide were used in order to cover a wide $\mathrm{pH}$ range (from 4 to 13). A $48 \mathrm{~h}$ liquid/solid contact time was chosen; previous studies have shown this to be sufficient to attain steady-state. In a maximum mobile fraction (MMF) test, the crushed waste was submitted to a sequence of successive leaching in batch corresponding to cumulative L/S ratios of 10 and 50. Each step took 24 hours under agitation. Demineralised water was used as leachant. The data of this second batch test were essential to characterise the initial chemistry of the waste pore fluids.

Unlike batch tests, dynamic leaching monolithic tests (DLMT) used monolithic samples, the experiments being performed over a period of several months to estimate the long-term behaviour of S/S waste. The experimental set-up consisted of a water reactor in which the cubic waste was completely immersed. The leachant was renewed at a constant flow rate of $250 \mathrm{ml} / \mathrm{h}$. Closed-system conditions prevented, or at least minimised, $\mathrm{CO}_{2}$ uptake. The dynamic leaching test was made at constant temperature $\left(18^{\circ} \mathrm{C}\right)$. The eluate was sampled at given times (at 24, 48, 72 hours then each 7 days during two months) for chemical analysis in order to follow the release of elements from the cubic waste. A blank run without $\mathrm{S} / \mathrm{S}$ waste was realised in a first stage. Results from an experimental blank, performed without $\mathrm{S} / \mathrm{S}$ waste, showed no significant contamination with the exception of silica, and to a lesser extent, sodium concentrations resulting from the borosilicate glass of the extracting device. The leachate $\mathrm{pH}$ was directly measured in the reactor vessel. The evolution of structural features and of mineral phases in the S/S samples after the leaching test was monitored by scanning electron microscope (SEM).

\subsection{Model features and thermodynamic data}

The reactive transport code HYTEC (van der Lee et al., 2003) was used to simulate the dynamic leaching tests taking into account diffusive transport of solutes and chemical reactions (aqueous chemistry, dissolution/precipitation and sorption. In HYTEC, diffusion is coupled to chemistry according to the following equation:

$$
\frac{\partial \omega \mathrm{c}_{\mathrm{i}}}{\partial \mathrm{t}}=\nabla \cdot\left(\mathrm{De} \nabla \mathrm{c}_{\mathrm{i}}\right)-\frac{\partial \omega \overline{\mathrm{c}}_{\mathrm{i}}}{\partial \mathrm{t}}
$$

where $\mathrm{c}_{\mathrm{i}}$ and $\bar{c}_{i}$ are the mobile and immobile concentration of a species per unit volume of solution respectively, $\omega$ is the porosity and De is the effective diffusion coefficient. The fixed or solid fraction is evaluated by the chemical calculations, whereas the aqueous fraction is a function of the transport processes. Chemistry and transport are coupled through a sequential iterative algorithm. In addition, the HYTEC code is strongly coupled, e.g. the effective diffusion coefficients change when mineral precipitation or dissolution modifies the local porosity. Thus, HYTEC allows accounting for clogging by carbonation, or to the contrary, for porosity increase by leaching of calcium hydroxide. Several porositydiffusion relations are found in the literature, some being specific to cements and concretes (Bentz and Garboczi, 1992). A modified version of the Archie's law, which is implemented in HYTEC, was used in a first attempt at modelling the feedback of chemistry on mass transport: 


$$
\operatorname{De}(\omega)=\operatorname{De}\left(\omega_{0}\right)\left(\frac{\omega-\omega_{c}}{\omega_{0}-\omega_{c}}\right)^{m}
$$

The parameter $\omega_{\mathrm{c}}$ is a critical porosity threshold under which diffusion stops and $\mathrm{m}$ is the empirical Archie coefficient ranging from 1.3 for unconsolidated sand to 2.2 for consolidated rocks. A zero porosity threshold and an Archie coefficient of 2 were used in this study.

The modelling of the closed-system DLMT set-up was made according to the generic configuration represented in Fig. 1: a monolithic waste immersed in a reactor, a permanent leachant renewal at a given rate, a fixed temperature, and a homogenisation of the reactor solution. Zero-flux boundary-conditions were defined at the lateral sides of the reactor, i.e. not at the $\mathrm{S} / \mathrm{S}$ waste limits. The leachant chemistry corresponded to a pure water solution ( $\mathrm{pH} \mathrm{7,} \mathrm{no} \mathrm{gas} \mathrm{neither} \mathrm{solute).} \mathrm{To} \mathrm{reduce} \mathrm{computation} \mathrm{time,} \mathrm{a}$ cylindrical geometry was used instead of a complete 3D-geometry (Fig. 1). At first approximation, the CPU time increases as $\mathrm{N}^{2}$ in $3 \mathrm{D}$-cylindrical geometry but as $\mathrm{N}^{3}$ in $3 \mathrm{D}$-cubic geometry $(\mathrm{N}$ being the number of grid nodes). The gain is therefore substantial and allows for a thiner discretization of the grid, i.e. a reduction of the node sizes, which was found to be more critical than geometry for modelling the waste evolution as discussed in section 4.2. Care was taken to minimize errors linked to the cylindrical geometry: i) the total mass of waste was unchanged, and ii) height and radius were chosen in order to minimise surface discrepancy between the cylinder (total surface $=88.5 \mathrm{~cm}^{3}$ ) and the cubic waste (total surface $\left.=96 \mathrm{~cm}^{3}\right)$. Furthermore, unlike 1D grid approximation, specific alterations occurring at the monolith edges are also, albeit less intensively, simulated in cylindrical geometry (see Fig. 1). However, the 3D-cylindrical approximation does not hold for advanced stages of the monolith degradation. In this study, the cubic monolith did not show any pronounced edge alterations after the dynamic leaching tests.

The chemical reactions were calculated assuming local thermodynamic equilibrium and using the B-dot activity model for ionic strength correction. The MINTEQ thermodynamic database (Allison et al., 1991), well suited for heavy metal chemistry, was selected and enriched with additional data. Table 1 provides details of the minerals selected for the present study. Calcium and silicate hydrate (CSH) is a generic term that includes a wide variety of poorly crystallised phases of continuously variable $\mathrm{Ca} / \mathrm{Si}$ ratio. To simulate the degradation of the cement phases, three $\mathrm{CSH}$ species of increasing $\mathrm{Ca} / \mathrm{Si}$ ratio were considered according to the experimental results obtained by Stronach and Glasser (1997). Two calcium aluminates, ettringite and a Friedel's salt, were also introduced in the calculations. Sodium and calcium sorption on $\mathrm{CSH}$ phases was also considered in an attempt at better simulating the long-term release of sodium. The corresponding surface complexation data are detailed in De Windt et al. (2004).

Several minerals observed in laboratory tests or field conditions were considered as potential candidates to control lead solubility in the modelling: the sulfate, anglesite; hydroxy-chlorides, blixite and laurionite; oxides, litharge and its precursor, a poorly crystalline hydroxide; and finally carbonates, hydrocerusite and cerusite; the later being relevant in case of open condition only. The formation of $\mathrm{Pb}(\mathrm{OH})_{2}$ in a pure hydroxylated form, which is present in both the MINTEQ and HATCHES (Hatches, 1991) databases, has not been characterised in the literature. It should be considered as a simplified formulation of more complex hydrous phases (Antenucci et al., 2004; Baltpurvins et al., 1996). A fitting procedure of the ANC results led to a formation constant $(\operatorname{logK})$ of -11 , close to the HATCHES data of $-11.9\left(25^{\circ} \mathrm{C}\right.$, basis components of Table 1).

\section{Modelling of pore water and lead solubility}

\subsection{Pore water chemistry of the $S / S$ waste}

The chemistry of $\mathrm{S} / \mathrm{S}$ waste pore fluids was difficult to analyse by direct means due to very low pore sizes and mechanical stiffness of the material, hence it was indirectly determined from MMF test modelling and mineralogical data. Pore fluids are assumed to be in thermodynamic equilibrium with the cement solid 
phases (Reardon, 1992). A local equilibrium approach was also considered for modelling the MMF tests in a first approximation. The kinetics of mineral dissolution is indeed fast in such tests due to high reactive surfaces of the crushed material, although the standardised duration of 24 hours was probably not sufficient as to reach a complete equilibrium state (Halim et al., 2005). Sodium ions were assumed to be both dissolved in pore fluids and sorbed on CSH surfaces. Potassium ions were only introduced in pore fluids since the same authors did not notice any significant sorbed fraction. The $\mathrm{pH}$ was calculated such as to maintain the electroneutrality of the solution which depends itself on the dissolved contents in alkaline ions (present as $\mathrm{NaOH}$ and $\mathrm{KOH}$ in pore fluids) and portlandite equilibrium. In our model, this last mineral controls the calcium concentration in pore water. Dissolved silica is only controlled by CSH 1.7 whereas sulfate and aluminium are in equilibrium with ettringinte. According to literature, but also to the leaching results, chlorides were supposed to be present in pore water as well as in solid phases, most probably a Friedel's salt (Glasser et al, 1999; Bothe and Brown, 2004).

Figure 2 depicts the evolution of aqueous concentrations and $\mathrm{pH}$ during the two sequential leaching steps of the MMF test. The calculated total aqueous concentrations of $\mathrm{K}$ and $\mathrm{Na}$ were set identical to the experimental concentrations at the outlet of the first leach step, the fixed fraction of sodium being almost zero at this stage. As leaching progresses, the agreement between measured and calculated results is still fairly good for $\mathrm{Na}$ and, to a lesser extent, for K. Calcium concentrations and $\mathrm{pH}$ are accurately estimated for both leaching steps. They are controlled by portlandite dissolution in the batch solution. The calculated silica concentration is significantly lower than the measured concentrations in the first leach step. Silica contents are not commonly provided in literature devoted to similar tests, essentially because of potential artifacts induced by glass materials. However, Islam et al. (2004a) report leachate saturated with respect to amorphous silica and, therefore, with respect to CSH. The dissolution of unreacted silica during cement hydration could be a possible explanation. The calculated silica aqueous concentration of the second leach step is in better agreement with the experimental data.

The modelled sulfate concentration, which is controlled by ettringite, is in good agreement with experimental results for the first leach step but less so for the second one. The calculated sulfate concentration was found to be quite sensitive to the aluminium concentration in a pure equilibrium approach. A pure conservative assumption turns out to be incorrect for chlorides demonstrating that, in addition to pore water content, a secondary mineral source has to be taken into account. However, it was not possible to accurately quantify the initial dissolved and solid fractions of chloride from the MMF results only. From a thermodynamical point of view, the Friedel's salt is totally dissolved at the first leach step yielding an aqueous content higher than the experimental one. Accordingly, in the second leach step, the calculated value resulting from a simple dilution effect is lower the measured data. Provided that the Friedel's salt assumption is relevant, the chloride concentration seems to be kinetically controlled.

Although trace content in oxide and hydroxide are found in cement-based materials, the bulk of lead is incorporated in the matrix of the CSH phases (Andac and Glasser, 1999; Badreddine et al., 2004). Whether lead fixation in such hydrated and low ordered solid phases proceeds by substitution of $\mathrm{Ca}^{2+}$ ions, or by sorption on the CSH skeleton, is still debated. Since CSH was modelled by using a solid solution approach in the present study, the same approach was adopted for modelling lead solubility. A substitution degree of 0.01 and 0.05 mole fraction was examined in turn, by assuming in a first approximation that the formation constants of CSH given in Table 1 were still suitable. Whatever the substitution degree, it appeared that lead solubility and release were better modelled by taking into account a solubility control by precipitation of secondary phases, such as lead hydroxide (and blixite in the ANC tests).

The modelled pore water chemistry of the $\mathrm{S} / \mathrm{S}$ waste, which is reported in Table 2, was estimated from the MMF results and mineralogy. Sodium, potassium and sulfates contents in cement pore water were calculated by taking into account the liquid/solid ratio of the first leach step and the porosity of the S/S waste. Sodium ions were again assumed to be both dissolved in pore fluids and sorbed on CSH surfaces 
(PW-B). The PW-A case, without sorption, is given for comparison. The calculated fixed fraction is relatively important, around 45\%, but within the range of values measured by Park and Batchelor (1999) on Portland cement pastes. The $\mathrm{pH}$ of pore water PW-B is thus lower than PW-A since a fraction of the total sodium inventory is fixed on $\mathrm{CSH}$. Calcium is still controlled by portlandite, and the higher the $\mathrm{pH}$, the lower its concentration. CSH1.7 and ettringite, which controlled Si and Al contents respectively, are in equilibrium with the pore solution. Calculation indicated that PW-A solution was close to equilibrium with Friedel's salt solid and PW-B slightly undersaturated. Again, it was difficult to accurately discriminate between the dissolved and solid fractions. Lead was controlled by both the dissolved, $\mathrm{Pb}(\mathrm{OH})_{3}{ }_{3}$, and the $\mathrm{Pb}(\mathrm{OH})_{2}(\mathrm{~s})$ solid disregarding sorption processes. The former aqueous complex explains the increase of lead concentration with $\mathrm{pH}$, comparing PW-A and PW-B pore waters of Table 2.

\subsection{Lead solubility versus $p H$}

Lead solubility is plotted against pH in Fig. 3. The data comes from the ANC test as well as from a similar investigation carried out by Sanchez et al (2002). These results are not essential for estimating the initial pore water chemistry but rather for modelling the release of lead during dynamic leaching tests characterised by a broader range of $\mathrm{pH}$. The amphoteric behaviour of lead accounts for the solubility minimum found between $\mathrm{pH} 8$ and 10 combined with sharp solubility increases in both acidic and alkaline conditions. Taking into account the logarithmic scale, modelling agrees relatively well with the whole experimental data set and correctly simulates the amphoteric profile. The strongest discrepancy occurs at low concentrations where lead solubility is sensitive to coprecipitation processes, which were disregarded in the present modelling by simplification. Modelling indicates that aqueous hydroxide complexes, $\mathrm{Pb}(\mathrm{OH})_{2}$ and $\mathrm{Pb}(\mathrm{OH})_{3}{ }_{3}$, are the main aqueous species under the alkaline conditions encountered in cementbased waste. Beside potential sorption processes not considered here, lead solubility is controlled by hydroxides at alkaline $\mathrm{pH}$, by blixite in the $\mathrm{pH}$ range 6 to 10, and by anglesite in the acidic domain. At the lowest $\mathrm{pH}$, lead concentration is not solubility controlled but rather limited by the total $\mathrm{Pb}$ content of the waste; which explains the flat curves below $\mathrm{pH} 4$ in Fig. 3. These theoretical results are supported by experimental investigations (Baltpurvins et al., 1996; Edwards et al, 1992; Sanchez et al., 2002).

\section{Modelling of the long term leaching tests}

\subsection{Diffusion, solubility and surface alteration}

The release of elements by cement-based materials is a combination of two extreme behaviours: diffusioncontrolled and solubility-controlled processes. The concentration gradient between the pore fluids and the leachant leads to the diffusion of chemical species out of the waste. The concentration gradient is progressively reduced as species migrate, which gives the well-known root-square time dependency of diffusion profiles. Diffusion takes place first in the outer zones of the monolith and gradually reaches the core of the samples. The S/S waste material behaves like a diffusion barrier itself. Another noteworthy point is that diffusion can lead to the total depletion of a given element in the case of strictly conservative elements whose unique source is pore water. Their flux eventually tends to zero, i.e. cumulative mass profile tends to a flat plateau. On the contrary, diffusion of elements controlled by mineral-source dissolution leads to an ever increasing cumulative release up to full depletion. Solubility-controlled release is usually coupled to changes in pore water chemistry.

Since there was no direct measurement of effective diffusion coefficients, De, an alternative was to fit by modelling the release profiles of sodium which can be considered as a relevant tracer for that purpose (Tits et al., 2003). The diffusion coefficient of $\mathrm{Na}$ was then assigned to all the other elements in a first approximation. Fig. 4 reports a sensitivity analysis on De ranging from $3 \times 10^{-13}$ to $3 \times 10^{-10} \mathrm{~m}^{2} / \mathrm{s}$ The release of sodium is clearly too fast with the largest value and too slow with the smallest one. The best fit was obtained with the intermediate value, $3 \times 10^{-12} \mathrm{~m}^{2} / \mathrm{s}$, by considering both the instantaneous flux and the cumulative mass of released sodium. This figure is within the range of values published in the literature 
for the same class of materials $\left(0.5-2 \times 10^{-12} \mathrm{~m}^{2} / \mathrm{s}\right.$ in MacCarter et al. (2000), $3 \times 10^{-12} \mathrm{~m}^{2} / \mathrm{s}$ in Tiruta-Barna et al. (2005). The simulation of the long-term release of $\mathrm{Na}$, i.e. beyond 40 days here, was improved while considering $\mathrm{Na}$ sorption. Diffusion of $\mathrm{Na}$ ions leads to a decrease of pore water concentrations and, consequently, to an almost proportional desorption of $\mathrm{Na}$ ions fixed on $\mathrm{CSH}$ phases representing a weak long-term source. About $85 \%$ of the total $\mathrm{Na}$ amount is eventually leached after 2 months.

The monolith surface represents a singular zone with respect to solubility-controlled processes. These zones of direct contact with the leaching solution are subjected to active dissolution mechanisms. The reactive transport model can account for such processes, but in practise they are not always very accurate, owing to grid limitations. For example, in the local equilibrium approach, CSH dissolution is prevented as long as portlandite is present in a node of the grid: therefore, the greater the node size, the later the beginning of $\mathrm{CSH}$ dissolution. Interpretating the experimental silica cumulative profiles in terms of alteration depth leads to thicknesses close to $0.3 \mathrm{~mm}$ after 62 days for the present $250 \mathrm{ml} / \mathrm{h}$ rate. This requires node sizes lower than $0.3 \mathrm{~mm}$. Table 3 reports the sensitivity of the calculated cumulative releases with respect to the refinement of the calculation grid. The node size ranges from 2.5 to $0.15 \mathrm{~mm}$. A first glance at Table 3 clearly shows two types of elements. The releases of $\mathrm{Na}$ and $\mathrm{K}$, which are mainly diffusion-driven, are independent of the grid refinement. The releases of $\mathrm{Ca}$ and $\mathrm{Si}$, which are globally controlled by surface leaching, are very sensitive to the node size. Furthermore, as expected, the lower the node size, the better the quality of the modelling. $\mathrm{Cl}, \mathrm{Pb}$ and $\mathrm{SO}_{4}$, which are both diffusion and solubility controlled, exhibit an intermediate behaviour. Another interesting aspect of Table 3 is the importance of considering porosity effects on diffusive transfers. Indeed, as discussed in section 4.3, there is a specific dissolution of portlandite and ettringite compared to the CSH network of the cement matrix. Such a hydrolysis pattern leads to an opening of the poral space and, consequently, to an increase of diffusion coefficients. When this process is taken into account in the calculations, the modelling results become a step closer to the experimental data for those elements which are surface sensitive $\left(\mathrm{Ca}, \mathrm{Si}\right.$ and $\left.\mathrm{SO}_{4}\right)$. Finally, it is worth mentioning that a kinetics approach can be physically more justified than a thermodynamic dissolution depending on the leachate chemistry. This is not the case in the present study since the thermodynamically calculated results are globally always below the experimental ones.

\subsection{Element release in the closed-system DLMT}

All the calculations presented in this section, and the next one, have been performed with a node size of $0.15 \mathrm{~mm}$ and a variable porosity.

Figure 5 reports $\mathrm{pH}$ data in the leachate over two months as well as $\mathrm{pH}$ profiles within the monolith and the reactor after two months. Globally, the modelling is in fair agreement with experiment. During the first days, diffusion of the alkaline plume $(\mathrm{Na}-\mathrm{K}-\mathrm{OH})$ and portlandite dissolution keeps $\mathrm{pH}$ at a value of 11 in the reactor. Then, the $\mathrm{pH}$ progressively drops by one unit. This steady-state comes from the balance between portlandite dissolution and the injection of pure water in the reactor vessel. After 1 month, the calculations are greater than the measured $\mathrm{pH}$ values. $\mathrm{CO}_{2}$ uptake experimental artifact could explain both the spread of data and the $\mathrm{pH}$ drop at the end of the dynamic leaching test. Within the monolith, the diffusion of the alkaline Na-K-OH plume leads to concentric profiles of $\mathrm{pH}$ values decreasing from the periphery to the core of the monolith. Portlandite buffers $\mathrm{pH}$ around 12.4 on the long term. The $\mathrm{pH}$ in the thin leached surface layer, free of portlandite, is about 11.

Figure 6 shows the cumulative mass of $\mathrm{K}, \mathrm{Ca}, \mathrm{Pb}, \mathrm{Si}, \mathrm{Cl}$ and $\mathrm{SO}_{4}$ for the closed-system DLMT. There is a good overall agreement between modelling and experimental data notwithstanding the contrasted chemistry and concentration range of these elements. Potassium follows an evolution similar to the sodium one since both are alkaline ions mainly present in the pore water. Calcium flux indicates a longterm release controlled by dissolution, in particular surface alteration processes of portlandite and CSH 1.7, as discussed above. There is a diffusive contribution in the modelling curve, and the experimental 
data, which is not simulated by the fitted approximation. The modelling/experiment agreement of lead release is fully satisfactory given the chemical complexity of this element. A relatively good correlation between $\mathrm{Ca}$ and $\mathrm{Pb}$ release profiles can be noted in instantaneous release flux, not shown here. This is consistent with the observation that lead is mostly present in CSH phases. On the other hand, the ratio of lead and calcium molal fluxes $(\sim 0.001)$ is well below the CSH molal fraction $(\sim 0.05)$. Lead solubility is thus probably controlled by a secondary phase precipitation as considered in the present modelling. The decrease of $\mathrm{Pb}$ release after a few days corresponds to a decrease in $\mathrm{pH}$. About $0.5 \%$ of total lead content is eventually leached.

Modelling shows that silica release is essentially related to surface alteration of the monolith, although the actual agreement with experiment is poor. A technical reason is still related to grid limitation. CSH 1.7 starts to dissolve only when portlandite has been completely dissolved in a node. However, this dissolution yields a release in calcium but not in silica since CSH 1.1 phases replace CSH 1.7 ones as shown in the following section. This is only a later stage that CSH 1.1 dissolution occurs, inducing a more pronounced release of silica. On the other hand, the factor ten discrepancy existing between modelling and experimental results is similar to the factor obtained in the modelling of MMF tests, indicating an additional reaction not simulated here or an experimental artifact. Chloride release results both from the diffusion of the initial pore water content, which explains most of the early release, and the dissolution of Friedel's salt within the monolith on the long term. Sulfate essentially behaves like calcium, i.e. its release is controlled by the dissolution of a solid phase (ettringite) at the monolith surface.

\subsection{Mineralogical evolutions}

All the calculated mineralogical transformations take place at the periphery of the monolith, i.e. at the waste/leachate interface. Dissolution of portlandite and ettringite as well as a transformation of CSH 1.7 to $\mathrm{CSH}$ of lower $\mathrm{C} / \mathrm{S}$ ratio (CSH 1.1, but not CSH 0.8 in our case) constitute the main alteration processes, as shown in Figure 7. Portlandite is completely leached over a thickness of $1.75 \mathrm{~mm}$ after 2 months. The front of CSH 1.7 alteration closely follows the front of portlandite dissolution. Ettringite dissolution forms a second, distinct and intermediate, front at $0.75 \mathrm{~mm}$. The CSH network is globally preserved in the leached area. CSH 1.1 phases are only dissolved over a thickness of $0.15 \mathrm{~mm}$ after 2 months. Figure 8 presents complementary mineralogical 2D-profiles. The dissolution front of Friedel's salt also proceeds from the surface to the inner space of the monolith, but it progresses more quickly than portlandite and ettringite dissolution fronts. If magnesium is introduced in the monolith, either as small amounts of magnesium hydroxide or hydrotalcite, the (re)precipitation of hydrotalcite is systematically calculated at the surface of the monolith where $\mathrm{pH}$ drops.

SEM observations carried out after the dynamic leaching test showed that the overall $\mathrm{Ca} / \mathrm{Si}$ of the CSH phases at the monolith surface decreased as the enhanced alteration progressed. Portlandite and ettringite dissolution, $\mathrm{CSH}$ evolution to lower $\mathrm{Ca} / \mathrm{Si}$ ratio, are pointed out by several authors for experimental investigations similar to the present DLMT test (Faucon et al., 1996; Harris et al., 2002; Islam et al., 2004a). The splitting between portlandite and ettringite dissolution fronts is reported by Islam et al. (2004a), the resistance of the CSH network to leaching by Faucon et al. (1996) and Harris et al. (2002). Precipitation of hydrotalcite at the monolith surface was observed by Faucon et al. (1996).

\section{Conclusions}

Modelling the initial state of the $\mathrm{S} / \mathrm{S}$ monolithic waste requires a preliminary characterisation by mineralogical analyses and batch leaching tests. A local equilibrium approach seems to be adequate in a first approximation. Modelling of dynamic leaching tests needs for a reactive transport model. The present model considers, simultaneously, the chemical evolution of pore water, the mineralogical alteration fronts induced by the sequential dissolution of the cement hydration products, and the concomitant release of elements from the $\mathrm{S} / \mathrm{S}$ waste. Globally, the simulated and experimental results are in good agreement. 
Element release mechanisms appear to be either mainly controlled by diffusion ( $\mathrm{Na}, \mathrm{K}$, and, to a lesser extent, $\mathrm{Cl})$, by surface dissolution $(\mathrm{Ca}, \mathrm{Si})$ or by a mixed evolution $\left(\mathrm{Pb}, \mathrm{SO}_{4}\right)$. All the calculated mineralogical transformations take place in a thin layer beyond the monolith surface. The monolith surface thus represents a singular zone with respect to solubility-controlled processes and, consequently, the releases of $\mathrm{Ca}, \mathrm{Si}$ and $\mathrm{SO}_{4}$ are quite sensitive to the node size of the simulation grid. The smaller the grid size, the better the agreement with experimental data. Modelling is further improved when the effect of mineral dissolution on porosity and effective diffusion coefficient is taken into account, as physically expected. In agreement with experimental literature, a front of CSH 1.7 alteration closely follows the front of portlandite dissolution. A second, distinct and intermediate, front is made by ettringite dissolution. A network of CSH is globally preserved in the leached layer. Precipitation of hydrotalcite is systematically calculated at the surface of the monolith. Further studies are now in progress, to both simulate the open condition DLMT (sensitive to carbonation and clogging processes), and to extrapolate the reactive transport model to in situ disposal conditions.

\section{Acknowledgments}

The editorial handling of Professor F. P. Glasser as well as constructive comments of two anonymous reviewers are gratefully acknowledged.

\section{References}

Allison, J.D., Brown, D.S., Novo-Gradac, K.J., 1991. MINTEQA2/PRODEF2, A Geochemical Assessment Model for Environmental Systems: Version 3.0 User's Manual. EPA/600/3-91/021. U.S. EPA, Athens, GA, 30605.

Andac, M., Glasser, F.P., 1999. Long-term leaching mechanisms of Portland cement-stabilized municipal solid waste fly ash in carbonated water. Cement Concr. Res. 29, 179-186.

Antenucci, D., Lorenzi, G., Leclerq, D., Veschkens, M., Yvon, J., Jdid, E., Nelsen, P., Dutré, V., 2004. Mineralogical status of metals in MSWI fly ashes solidified/stabilized in cement and long term stored in landfill. In: ICAM04. São Paulo (BR), 407-410.

Atkinson, A., Nickerson, A., 1988. Diffusion and sorption of cesium, strontium and iodine in watersaturated cement. Nucl. Technol. 81, 100-113.

Badreddine, R., Humez, A.-N., Mingelgrin, U., Benchara, A., Meducin, F., Prost, R., 2004. Retention of trace metals by solidified/stabilized wastes: Assessment of long-term metal release. Environ. Sci. Technol. 38, 1383-1398.

Baltpurvins, K.A., Burns, R.C., Lawrance, G.A., Stuart, A.D., 1996. Use of the solubility domain approach for the modeling of the hydroxide precipitation of heavy metals from wastewater. Environ. Sci. Technol. 30,1493-1499.

Baranger, P., Azaroual, M., Freyssinet, P., Lanini, S., Piantone, P., 2002. Weathering of a MSW bottom ash heap: a modelling approach. Waste Manag. 22, 173-179.

Bennet, D., Read, D., Atkins, M., Glasser, F., 1992. A thermodynamic model for blended cements. II: Cement hydrate phases, thermodynamic values and modelling studies. J. Nucl. Mater. 190, 315-325.

Bentz, D., Garboczi, E., 1992. Modelling the leaching of calcium hydroxide from cement paste: effect on pore space percolation and diffusivity. Mater. Struct. 25, 523-533.

Bothe, J., Brown, P., 2004. PhreeqC modeling of Friedel's salt equilibria at 23C. Cement Concr. Res. 34, 1057-1063.

De Windt, L., Pellegrini, D., van der Lee, J., 2004. Coupled modeling of cement/claystone interactions and radionuclide migration. J. Cont. Hydr. 68, 165-182.

Edwards, R., Gillard, R.D., Williams, P.A., Pollard, A.M., 1992. Studies of secondary mineral formation in the $\mathrm{PbO}-\mathrm{H}_{2} \mathrm{O}-\mathrm{HCl}$ system. Miner. Manag. 56, 53-65.

Faucon, P., Le Bescop, P., Adenot, F., Bonville, P., Jacquinot, J., Pineau, F., Felix, B., 1996. Leaching of cement: Study of the surface layer. Cement Concr. Res. 26, 1707-1715. 
Garrabrants, A., Sanchez, F., Kosson, D., 2003. Leaching model for a cement mortar exposed to intermittent wetting and drying. AIChE 49, 1317-1333.

Glasser, F., Kindness, A., Stronach, S., 1999. Stability and solubility relationships in AFm phases. Part I. Chloride, and hydroxide. Cement Concr. res. 29, 861-866.

Halim, C., Short, S., Scott, J., Amal, R., Low, G., 2005. Modelling the leaching of Pb, Cd, As, and Cr from cementitious waste using PHREEQC. J. Hazard. Mater. 125, 45-61.

Harris, A., Manning, M., Tearle, W., Tweed, C., 2002. Testing of models of the dissolution of cementsleaching of synthetic CSH gels. Cement Concr. Res. 32, 731-746.

Hatches, 1991. Hatches-r10, database for radio chemical modelling. Tech. rep., NEA.

Islam, M., Catalan, L., Yanful, E., 2004a. Effect of remineralization on heavy-metal leaching from cement-stabilized/solidified waste. Environ. Sci. Technol. 38, 1561-1568.

Islam, M., Catalan, L., Yanful, E., 2004b. A two-front leach model for cement-stabilized heavy metal waste. Environ. Sci. Technol. 38, 1522-1528.

MacCarter, W.J., Starrs, G., Chrisp, T.M., 2000. Electrical conductivity, diffusion, and permeability of Portland cement-based mortars. Cement Concr. Res. 30, 1395-1400.

Park, J., Batchelor, B., 1999. Prediction of chemical speciation in stabilized/solidified wastes using a general chemical equilibrium model. II: Doped waste contaminants in cement porewaters. Cement Concr. Res. 29, 99-105.

Park, J., Batchelor, B., 2002. A multi-component numerical leach model coupled with a general chemical speciation code. Water Res. 36, 156-166.

Perkins, R., Palmer, C., 1999. Solubility of ettringite $\left(\mathrm{Ca}_{6}\left[\mathrm{Al}(\mathrm{OH})_{6}\right]_{2}\left(\mathrm{SO}_{4}\right)_{3} \cdot 26 \mathrm{H}_{2} \mathrm{O}\right)$ at $5-75^{\circ} \mathrm{C}$. Geochim. Cosmochim. Acta 63, 1969-1980.

Reardon, E.J., 1992. Problems and approaches to the prediction of the chemical composition in cement/water systems. Waste Manag. 12, 221-239.

Sanchez, F., Gervais, C., Garrabrants, A.C., Barna, R., Kosson, D.S., 2002. Leaching of inorganic contaminants from cement-based waste materials as a result of carbonation during intermittent wetting. Waste Manag. 22, 249-260.

Stronach, S.A., Glasser, F. P., 1997. Modeling the impact of abundant geochemical components on phase stability and solubility of the $\mathrm{CaO}-\mathrm{SiO}_{2}-\mathrm{H}_{2} \mathrm{O}$ systems at $25^{\circ} \mathrm{C}: \mathrm{Na}^{+}, \mathrm{K}^{+}, \mathrm{SO}_{4}{ }^{2-}, \mathrm{Cl}^{-}$and $\mathrm{CO}_{3}{ }^{2-}$. Adv. Cement. Res 9, 167-181.

Tiruta-Barna, L., Imyim, A., Barna, R., 2004. Long-term prediction of the leaching behavior of pollutants from solidified wastes. Adv. Envir. Res. 8, 697-711.

Tiruta-Barna, L., Rethy, Z., Barna, R., 2005. Release dynamic process identification for a cement based material in various leaching conditions. Part II. Modelling the release dynamics for different leaching conditions. J. Envir. Manag. 74, 127-139.

Tits, J., Jakob, A., Wieland, E., Spieler, P., 2003. Diffusion of tritiated water and ${ }^{22} \mathrm{Na}^{+}$through nondegraded hardened cement pastes. J. Cont. Hydr. 61, 45-62.

van der Lee, J., De Windt, L., 2001. Present state and future directions of modeling geochemistry in hydrogeological systems. J. Cont. Hydr. 47, 265-282.

van der Lee, J., De Windt, L., Lagneau, V., Goblet, P., 2003. Module-oriented modeling of reactive transport with HYTEC. Comput. Geosc. 29, 265-275.

van der Sloot, H., 1996. Developments in evaluating environmental impact from utilization of bulk inert wastes using laboratory leaching tests and field verification. Waste Manag. 16, 65-81. 
Table 1

Reactions and equilibrium constants for minerals used in the calculations.

\begin{tabular}{|c|c|c|c|}
\hline Mineral & Reaction & $\begin{array}{c}\operatorname{LogK}(25 \\
\left.{ }^{\circ} \mathrm{C}\right)\end{array}$ & Ref. \\
\hline Brucite & $\mathrm{Mg}^{2+}+2 \mathrm{H}_{2} \mathrm{O} \rightarrow \mathrm{Mg}(\mathrm{OH})_{2}+2 \mathrm{H}^{+}$ & -16.8 & [a] \\
\hline Calcite & $\mathrm{Ca}^{2+}+\mathrm{CO}_{3}{ }^{2-} \rightarrow \mathrm{CaCO}_{3}$ & 8.5 & [a] \\
\hline CSH 0.8 & $0.8 \mathrm{Ca}^{2+}+\mathrm{H}_{4} \mathrm{SiO}_{4}-0.4 \mathrm{H}_{2} \mathrm{O} \rightarrow \mathrm{CSH} 0.8+1.6 \mathrm{H}^{+}$ & -11.1 & [b] \\
\hline CSH 1.1 & $1.1 \mathrm{Ca}^{2+}+\mathrm{H}_{4} \mathrm{SiO}_{4}+0.2 \mathrm{H}_{2} \mathrm{O} \rightarrow \mathrm{CSH} 1.1+2.2 \mathrm{H}^{+}$ & -16.7 & [b] \\
\hline CSH 1.8 & $1.8 \mathrm{Ca}^{2+}+\mathrm{H}_{4} \mathrm{SiO}_{4}+1.6 \mathrm{H}_{2} \mathrm{O} \rightarrow \mathrm{CSH} 1.7+3.6 \mathrm{H}^{+}$ & -32.6 & [b] \\
\hline Ettringite & $\begin{array}{l}2 \mathrm{Al}^{3+}+6 \mathrm{Ca}^{2+}+3 \mathrm{SO}_{4}^{2-}+38 \mathrm{H}_{2} \mathrm{O} \rightarrow \\
\mathrm{Ca}_{6} \mathrm{Al}_{2}\left(\mathrm{SO}_{4}\right)_{3}(\mathrm{OH})_{12}: 26 \mathrm{H}_{2} \mathrm{O}+12 \mathrm{H}^{+}\end{array}$ & -56.9 & {$[\mathrm{c}]$} \\
\hline Friedel's salt & $\begin{array}{l}4 \mathrm{Ca}^{2+}+2 \mathrm{Al}^{3+}+2 \mathrm{Cl}^{-}+16 \mathrm{H}_{2} \mathrm{O} \rightarrow \mathrm{Ca}_{4} \mathrm{Al}_{2} \mathrm{Cl}_{2}(\mathrm{OH})_{12}: 4 \mathrm{H}_{2} \mathrm{O}+ \\
12 \mathrm{H}^{+}\end{array}$ & -73.0 & [d] \\
\hline Gibbsite & $\mathrm{Al}^{3+}+3 \mathrm{H}_{2} \mathrm{O} \rightarrow \mathrm{Al}(\mathrm{OH})_{3}+3 \mathrm{H}^{+}$ & -8.8 & [a] \\
\hline Gypsum & $\mathrm{Ca}^{2+}+\mathrm{SO}_{4}{ }^{2-}+2 \mathrm{H}_{2} \mathrm{O} \rightarrow \mathrm{CaSO}_{4}: 2 \mathrm{H}_{2} \mathrm{O}$ & 4.9 & [a] \\
\hline Hydrotalcite & $2 \mathrm{Al}^{3+}+4 \mathrm{Mg}^{2+}+10 \mathrm{H}_{2} \mathrm{O} \rightarrow \mathrm{Mg}_{4} \mathrm{Al}_{2} \mathrm{O}_{4}(\mathrm{OH})_{6}+14 \mathrm{H}^{+}$ & -73.8 & {$[\mathrm{e}]$} \\
\hline Portlandite & $\mathrm{Ca}^{2+}+2 \mathrm{H}_{2} \mathrm{O} \rightarrow \mathrm{Ca}(\mathrm{OH})_{2}+2 \mathrm{H}^{+}$ & -22.7 & [a] \\
\hline Anglesite & $\mathrm{Pb}^{2+}+\mathrm{SO}_{4}{ }^{2-} \rightarrow \mathrm{PbSO}_{4}$ & 7.8 & [a] \\
\hline Cerussite & $\mathrm{Pb}^{2+}+\mathrm{CO}_{3}{ }^{2-} \rightarrow \mathrm{PbCO}_{3}$ & 13.1 & [a] \\
\hline Hydrocerussite & $3 \mathrm{~Pb}^{2+}+2 \mathrm{CO}_{3}^{2-}+2 \mathrm{H}_{2} \mathrm{O} \rightarrow \mathrm{Pb}_{3}\left(\mathrm{CO}_{3}\right)_{2}(\mathrm{OH})_{2}+2 \mathrm{H}^{+}$ & 17.5 & [a] \\
\hline Laurionite & $\mathrm{Pb}^{2+}+\mathrm{Cl}^{-}+\mathrm{H}_{2} \mathrm{O} \rightarrow \mathrm{PbClOH}+\mathrm{H}^{+}$ & -0.6 & [a] \\
\hline Litharge & $\mathrm{Pb}^{2+}+\mathrm{H}_{2} \mathrm{O} \rightarrow \mathrm{PbO}_{2}+2 \mathrm{H}^{+}$ & -12.7 & [a] \\
\hline $\mathrm{Pb}(\mathrm{OH})_{2}$ & $\mathrm{~Pb}^{2+}+2 \mathrm{H}_{2} \mathrm{O} \rightarrow \mathrm{Pb}(\mathrm{OH})_{2}+2 \mathrm{H}^{+}$ & -11.0 & {$[\mathrm{f}]$} \\
\hline $\mathrm{Pb}(\mathrm{OH})_{3} \mathrm{Cl}$ & $2 \mathrm{~Pb}^{2+}+\mathrm{Cl}^{-}+3 \mathrm{H}_{2} \mathrm{O} \rightarrow \mathrm{Pb}(\mathrm{OH})_{3} \mathrm{Cl}+3 \mathrm{H}^{+}$ & -8.8 & [a] \\
\hline
\end{tabular}

[a] Allison et al. (1991), [b] fit from Stronach and Glasser (1997), [c] Perkins and Palmer (1999), [d] Bothe and Brown (2004),

[e] Bennet et al. (1992), [f] Adjusted LogK from the Hatches database (see subsection 3).

Table 2

Calculated chemistry of pore water without considering (PW-A) or considering (PW-B) the sorption of $\mathrm{Na}$ on $\mathrm{CSH}$ phases.

\begin{tabular}{lllll}
\hline & PW-A & & PW-A & \\
\hline $\mathrm{pH}$ & 13.7 & & 13.3 & \\
$\mathrm{Na}^{+}$ & 16550 & $\mathrm{mg} / \mathrm{l}$ & 8800 & $\mathrm{mg} / \mathrm{l}$ \\
$\mathrm{K}^{+}$ & 4100 & $\mathrm{mg} / \mathrm{l}$ & 4100 & $\mathrm{mg} / \mathrm{l}$ \\
$\mathrm{Ca}^{2+}$ & 22 & $\mathrm{mg} / \mathrm{l}$ & 64 & $\mathrm{mg} / \mathrm{l}$ \\
\hline
\end{tabular}




\begin{tabular}{lllll}
\hline $\mathrm{Pb}^{2+}$ & 135 & $\mathrm{mg} / \mathrm{l}$ & 57 & $\mathrm{mg} / \mathrm{l}$ \\
$\mathrm{Al}^{3+}$ & 3 & $\mathrm{mg} / 1$ & 0.08 & $\mathrm{mg} / \mathrm{l}$ \\
$\mathrm{H}_{4} \mathrm{SiO}_{4}$ & 658 & $\mathrm{mg} / \mathrm{l}$ & 99 & $\mathrm{mg} / \mathrm{l}$ \\
$\mathrm{Cl}^{-}$ & 5050 & $\mathrm{mg} / 1$ & 5050 & $\mathrm{mg} / \mathrm{l}$ \\
$\mathrm{SO}_{4}{ }^{2-}$ & 1267 & $\mathrm{mg} / 1$ & 1250 & $\mathrm{mg} / \mathrm{l}$ \\
\hline
\end{tabular}

Table 3

Sensitivity of the calculated cumulative releases ( $\mathrm{mg} / \mathrm{kg}$ of solid) with respect to the refinement of the calculation grid.\}

\begin{tabular}{llllllll}
\hline Node size $(\mathrm{m})$ & $\mathrm{Na}$ & $\mathrm{K}$ & $\mathrm{Ca}$ & $\mathrm{Pb}$ & $\mathrm{H}_{4} \mathrm{SiO}_{4}$ & $\mathrm{Cl}$ & $\mathrm{SO}_{4}$ \\
\hline $2.5 \times 10^{-3}$ & 1100 & 285 & 1290 & 11 & 4.5 & 670 & 80 \\
$1.25 \times 10^{-3}$ & 1100 & 285 & 2750 & 35 & 6 & 760 & 80 \\
$6.25 \times 10^{-4}$ & 1100 & 285 & 4585 & 54 & 13.5 & 760 & 96 \\
$3.1 \times 10^{-4}$ & 1100 & 285 & 5000 & 63 & 58 & 715 & 125 \\
$1.5 \times 10^{-4}$ & 1100 & 285 & 5000 & 67 & 250 & 715 & 150 \\
$1.5 \times 10^{-4}(*)$ & 1100 & 285 & 9200 & 132 & 2050 & 715 & 240 \\
& & & & & & & \\
Experimental & 1050 & 350 & 15840 & 70 & 12750 & 500 & 245 \\
\hline
\end{tabular}

$(*)$ This simulation takes into account the feedback of mineralogical evolution on porosity and diffusion coefficient. 

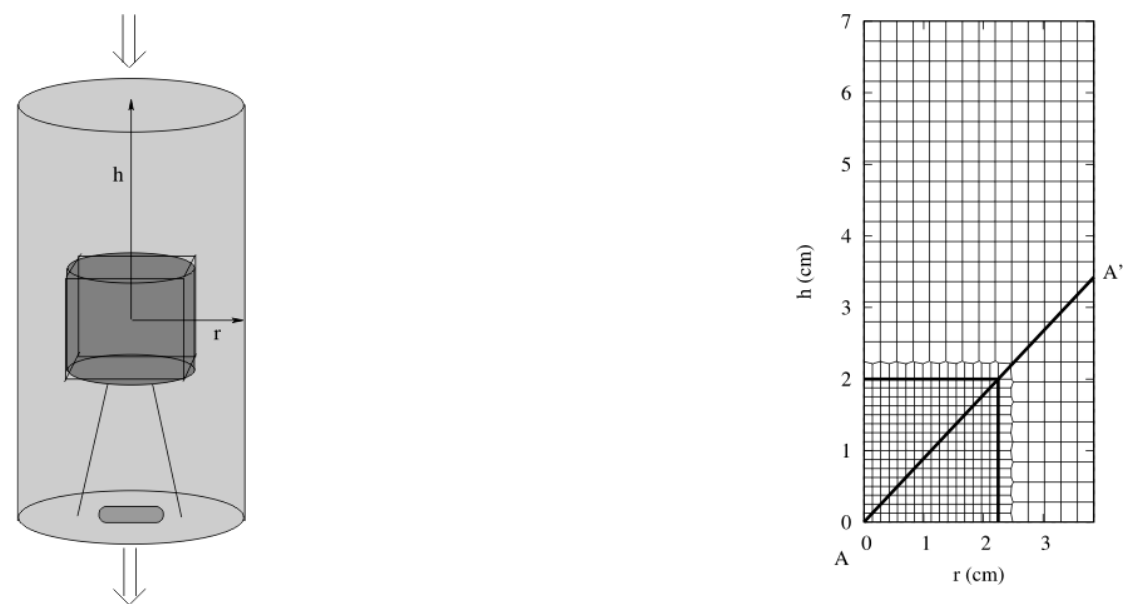

Fig.1. Zoom on the reactor zone of the dynamic leaching test applied to the monolithic waste (left) and one of the calculation grids assuming cylindrical symmetry (right).
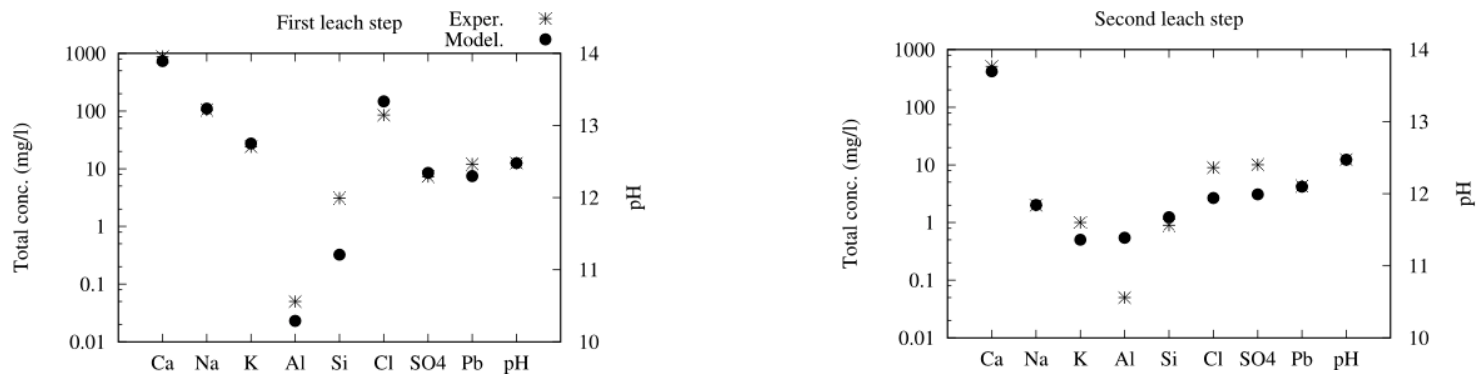

Fig.2. Evolution of aqueous concentrations and $\mathrm{pH}$ during the sequential leaching steps of the MMF test.

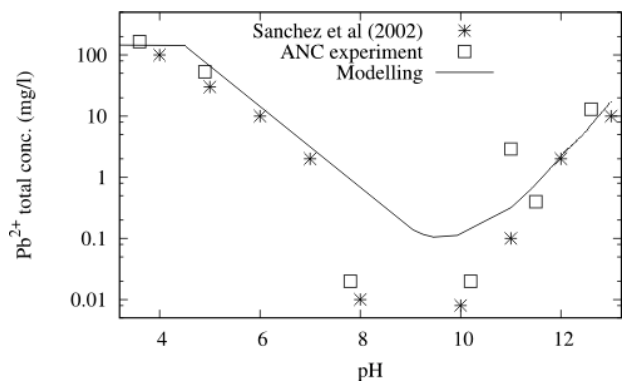

Fig.3. Solubility of lead as a function of $\mathrm{pH}$ (closed-system conditions). 

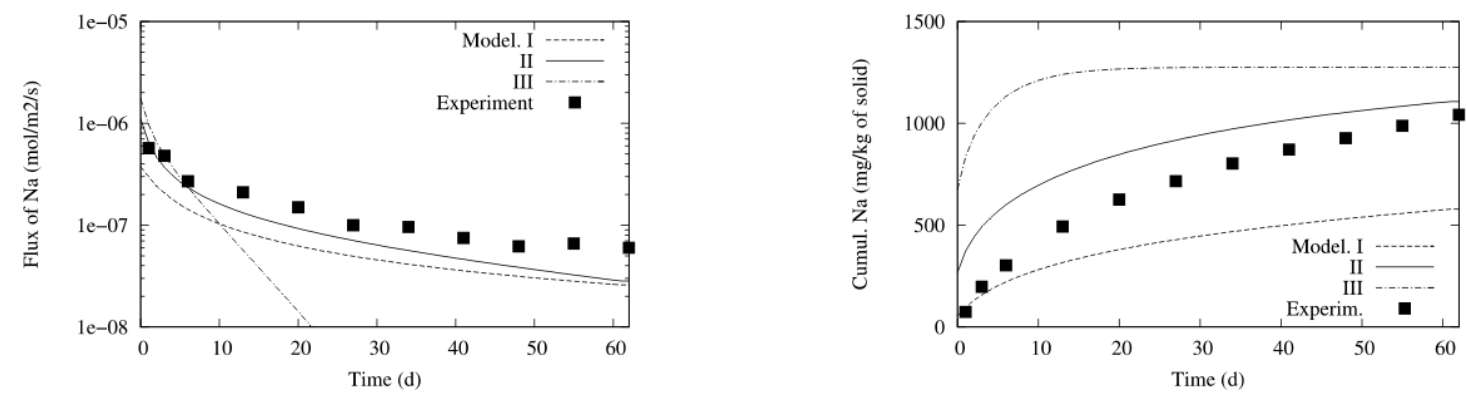

Fig. 4. Sensitivity of the released instantaneous flux and cumulative mass of sodium with respect to the effective diffusion coefficient: $\mathrm{De}=3 \times 10^{-10} \mathrm{~m}^{2} / \mathrm{s}$ (test-case I), De $=3 \times 10^{-12} \mathrm{~m}^{2} / \mathrm{s}$ (test-case II), and De $=$ $3 \times 10^{-13} \mathrm{~m}^{2} / \mathrm{s}$ (test-case III).
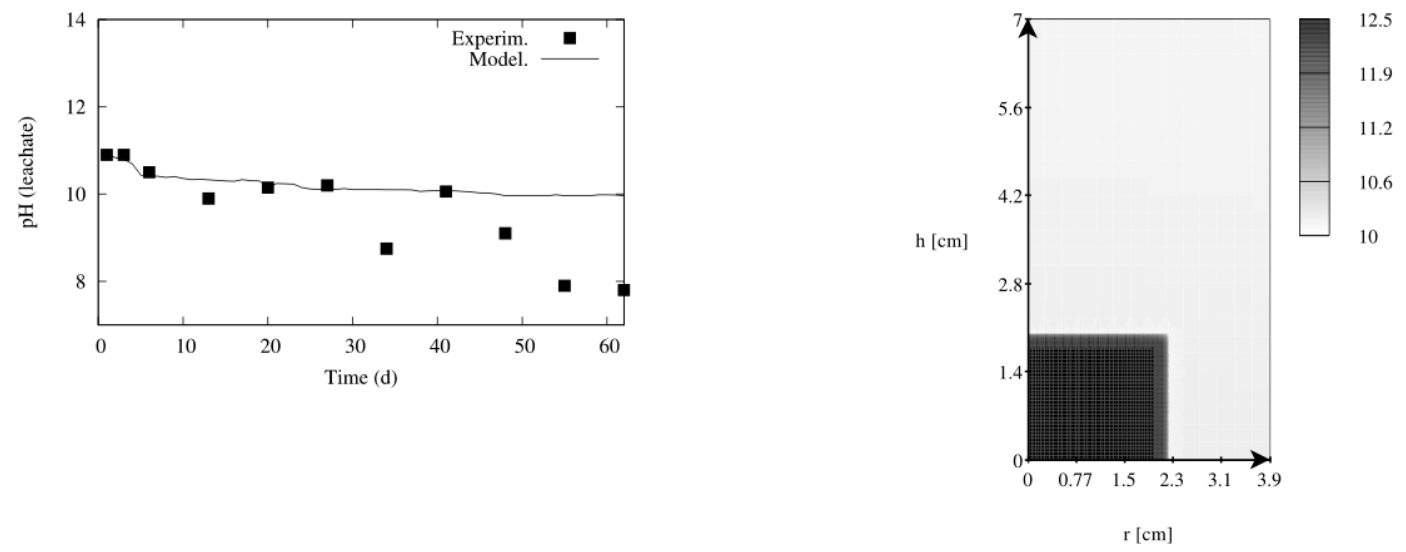

Fig. 5. Evolution of $\mathrm{pH}$ in the leachate solution of the reactor (left) and $\mathrm{pH}$ profile after 62 days (right). 

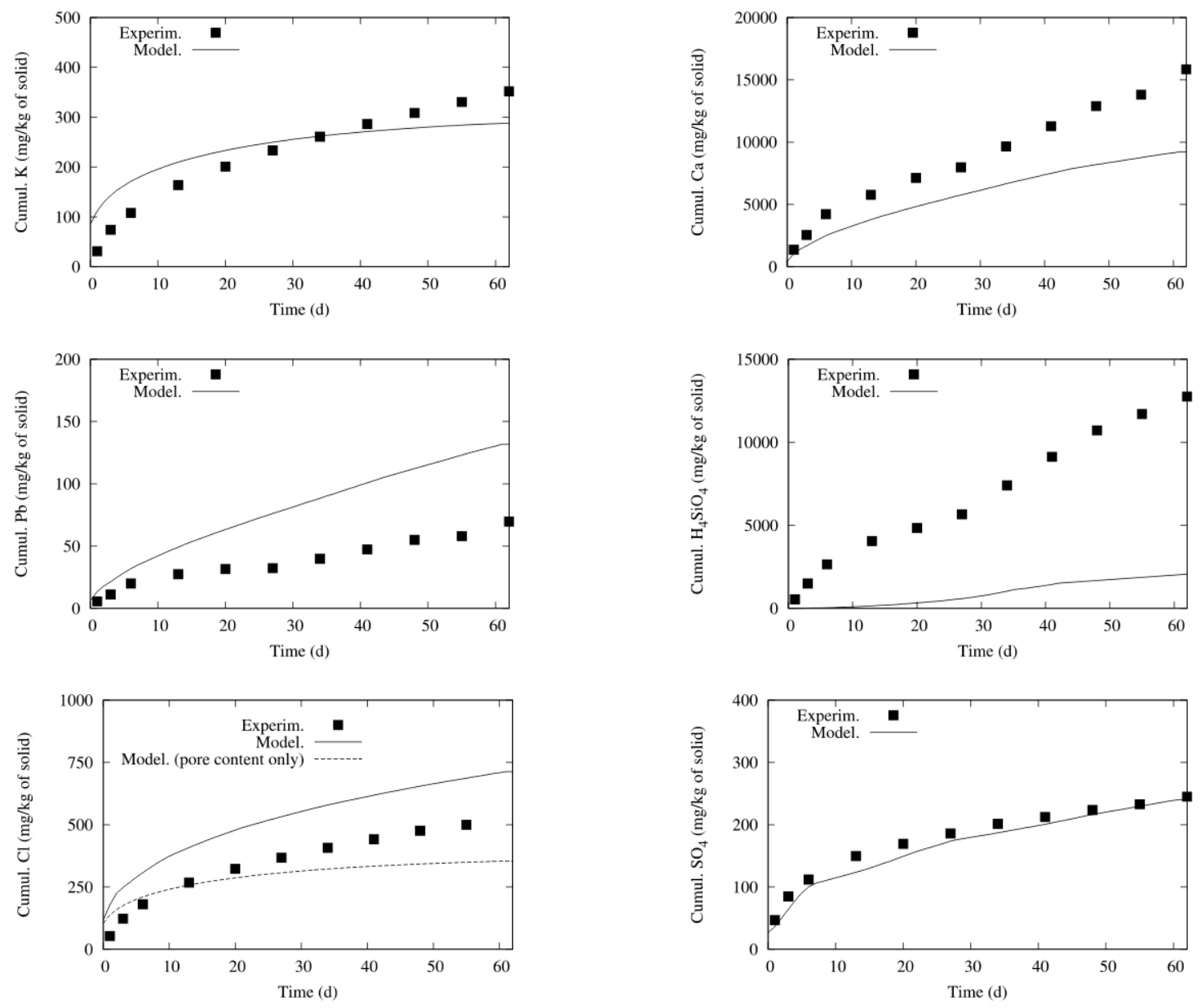

Fig. 6. Released cumulative mass of elements.
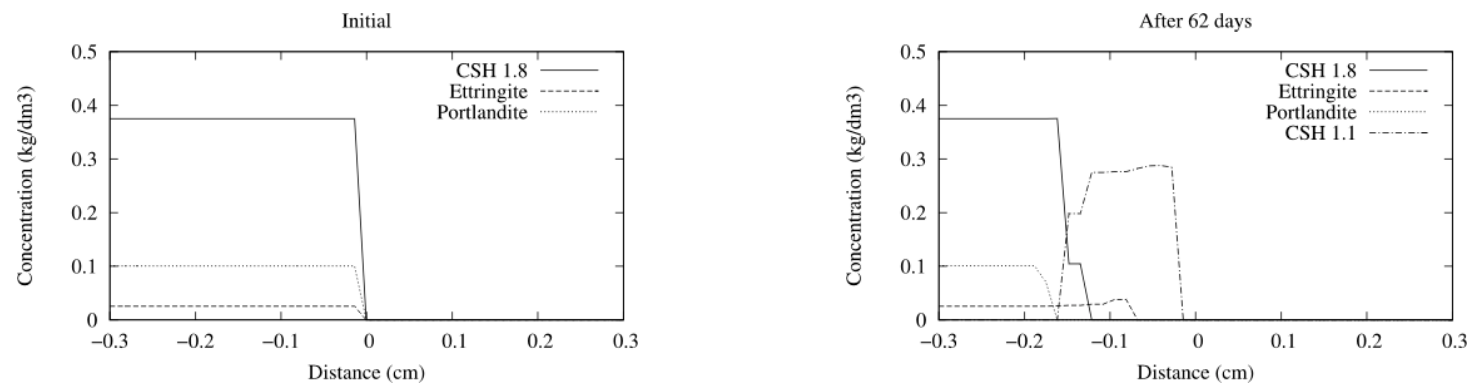

Fig. 7. Surface alteration of the monolithic S/S waste (1D profile along the segment A-A' of Fig.1). 

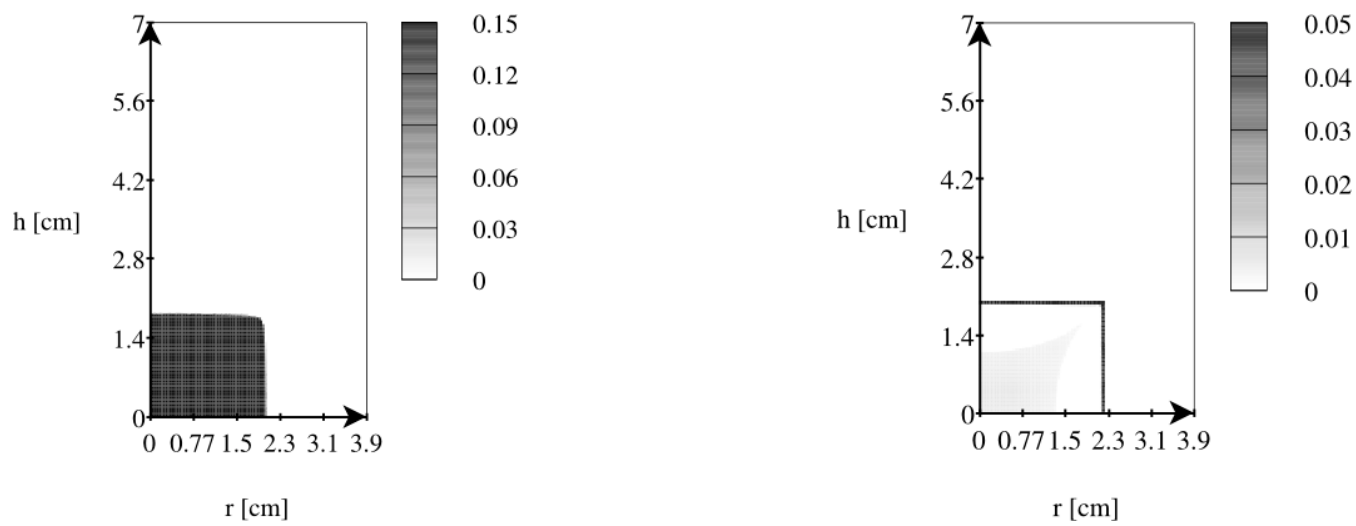

Fig. 8. Dissolution of Friedel's salt (left) and precipitation of hydrotalcite (right) after 62 days. 